\title{
Inheritance and Development of Ancient Buildings Culture based on Digital Image Technology
}

\author{
Jicong Wang ${ }^{1 *}$, Min $\mathrm{Li}^{1}$, Jia Wang ${ }^{1}$, Xiaoqing $\mathrm{Ma}^{1}$ \\ ${ }^{1}$ Art College, Jiangxi University of Finance and Economics, Nanchang City, Jiangxi Province, 330013, China
}

\begin{abstract}
Given the glorious achievements China boasts in the construction of ancient buildings, developing digital image technology for exploring the existing ancient buildings is of great significance, which cannot only analyse ancient civilization thoroughly, but also provide a reference for the field of modern architecture. It is efficient and accurate to collect information of ancient buildings by using modern digital image technology. However, it also has the drawbacks of having enormous sources which cannot be directly applied to image transmission. How to simplify the miscellaneous information resources and combine them with the ancient architectural culture is the key and difficult points of this study. In order to overcome the problem caused by incomplete information and lack of cultural concepts in ancient architecture construction, this paper explores the cultural connotation of ancient architecture from two aspects-material culture and intangible culture. When high-quality ancient architectural culture is demonstrated through modern digital image technology, ancient architectural culture is further promoted with the help of a variety of media platforms, so as to provide a reference for the inheritance and development of Chinese ancient architectural culture.
\end{abstract}

\section{Introduction}

With the development and progress of the times, the economy, education, science and technology of human society have developed to an unprecedented level. People pay more and more attention to cultural literacy and spiritual life. Ancient architectural relics are the carrier of Chinese long-standing culture. They reflect the political and economic conditions of different periods in China, serving as the basis for us to study Chinese ancient culture.

\section{The importance and practical significance of digital image technology for ancient architectural culture}

\subsection{The importance of digital image technology to the spread of ancient architectural culture}

Through the baptism of long history, ancient buildings become fragile and vulnerable. In this case, it will be fatal to the buildings if it is repaired or opened to visit. We urgently need a kind of technology to complete the research on ancient buildings without destroying them. In recent years, with the rapid development of digital image technology, AR (augmented reality), VR (virtual reality) and MR (hybrid reality) technologies have emerged one after another. Accurate digital models can be used to study ancient architectural culture. The superior simulation effect of modern digital image technology makes it possible for us to study it without contact, which meets the needs of the masses to understand the ancient architectural culture.

\subsection{Practical significance of digital image technology for ancient architectural culture}

Culture is the soul of a city. Through ancient architectural relics, the rich cultural connotation of a city can be seen. As is known, image is the most direct media which has the incomparable communication effect of words and pictures. In the past years, two-dimensional image has been an excellent carrier of cultural communication. With the development of image technology, digital image technology which is based on three-dimensional image technology comes into being. With strong visual effect and high-efficiency human-computer interaction, the major market is quickly occupied. Today, the development of tourism motivates local governments to strengthen the propaganda of local culture. Ancient buildings are more and more valued by the public as a model of culture. The combination of ancient architectural culture with digital image technology, which accords with the public cognition, can make tourism more competitive.

\footnotetext{
*Corresponding author e-mail: 1831859197@qq.com
} 


\section{Main problems in the development of digital image of ancient buildings}

\subsection{A large number of kinds of ancient buildings with incomplete construction information}

There are a great majority of ancient buildings in China, which can be divided into residential buildings, palaces, temples, religious buildings, garden buildings, mausoleum buildings, and urban buildings according to their application purposes. The rich types of ancient buildings correspond to various restoration methods[1]. How to find their commonness and integrate the restoration methods of ancient buildings into the digital image technology is an important problem we are facing.

Over the long history of ancient buildings, their initial construction drawings and other information have been lost, and the accurate data of ancient buildings owned by cultural relics protection units are limited. The traditional method to restore ancient buildings is to extract data information from the mapping drawings for reconstruction. However, this method is inaccurate and prone to deviation when data information is converted. At present, file protection is widely adopted by cultural relic protection units for the protection of cultural relics such as ancient buildings, which will produce a large number of drawings, tables, texts and image materials[2]. However, the material is not easy to use, and cannot clearly display physical data and inner construction of the buildings.

\subsection{Serious damage of ancient buildings}

The protection and restoration of ancient buildings has always been a controversial topic in academic circle. On the one hand, due to the influence of time and weather, the shape of ancient buildings will be damaged by wind and sun, leaving ancient buildings difficult to maintain the original appearance. On the other hand, some of the old buildings cannot meet the aesthetic needs of people with the continuous acceleration of urbanization[3]. Since more and more imitated ancient buildings have been built, the old and new buildings are mixed, losing the original appearance. Without the support of accurate data on ancient buildings, the digital image technology restoration or the later betterment of cultural relics can only be conducted based on the actual situation of the buildings or learn from similar ancient building structure of this kind by digital image technology, which is bound to change the traditional style of ancient buildings.

\subsection{Inadequate cultural information introduction}

As a historical and cultural heritage, ancient architecture and cultural tourism are inextricably linked. How to effectively spread the value and culture of ancient architecture to people is the primary problem to be solved. Some commercial product content will be embedded in the traditional image transmission of ancient buildings, or the transmission becomes sole product promotion. The strong commercial atmosphere will decrease the enthusiasm of the masses to explore culture and undermine the significance of promote ancient architectural culture as well. Without the laud of the "Preface to Tengwang Pavillion", Tengwang Pavillion will not be so attractive to public any more, and without poems concerned with Yellow Crane Tower, the building will not be so well-known. The significance of the dissemination of ancient architectural culture lies in sending cultural value concept to consumers, so that they can obtain spiritual resonance and value recognition when these consumers visit the ancient architectures.

\section{Restoration of ancient buildings and cultural communication under the background of digital image technology}

Ancient architectural culture can be divided into tangible material culture and intangible Cultural, which are respectively reflected in its superb construction technology and spiritual culture given by later generations. Ancient architecture has gone through a long historical road for which countless literati and scholars wrote poems and eulogies that have become a part of the culture of ancient architecture, even beyond the architecture itself. These two parts are important elements of ancient architectural culture, therefore the restoration of ancient architecture and cultural communication through the digital image technology shall also focus on these two parts.

\subsection{Establishment and simplification of parameterized digital structure of ancient buildings}

Data acquisition is the foundation of building 3D digital image. The traditional method is to organize manpower to collect and measure on the spot, by which a large number of surveying and mapping drawings, documents of ancient architectural engineering are collected. With the development of technology, a non-contact information acquisition method which is based on multi view $3 \mathrm{D}$ laser scanning and digital image photography modeling has emerged. Since the ancient building technology is complex with diverse structure the data which is obtained by 3D laser scanning and photography is huge and miscellaneous, so the modeling data cannot be directly used as materials for the promotion of ancient building culture. And these two ways are focusing on collecting the information of the surface of building, unable to explore the internal structure of ancient building.

Since single digital image technology cannot deal with the rich structure system of ancient buildings, it is necessary to integrate new technologies in the process of its restoration. After the improvement of each dynasty, the construction technology has formed a strict construction form and system in the Ming and Qing Dynasties, which provides convenience for our digital restoration work. Most of the ancient buildings left in China are in the Ming and Qing Dynasties, when the ancient buildings have been structured and modeled as a whole, which are divided into three parts: the house foundation, the house body and the roof, including beams, columns, walls, braces, doors, 
windows, brackets and other structures[4]. Combined with the idea of modular system in Chinese literature such as the construction method and the garden metallurgy, we can speculate and design the internal structure whose information cannot be collected by modern information technology on the surface, and manually supplement its three-dimensional model data. Based on the construction information and drawings of the cultural relics protection units, and according to the data resources collected from 3D laser scanning model and digital image photography modeling, the digital model with huge number of model planes will be simplified, expanded and reconstructed so that it can be widely used in image transmission.

\subsection{High-precision digital image simulation of ancient building materials}

The corrosion of main body and falling off of materials are the important problems with which the current ancient buildings are faced. The decoration of ancient Chinese architecture is rich and colorful with exquisite materials and crafts. In the process of digital image restoration, new materials cannot be used blindly, otherwise, the sense of history of ancient buildings will be destroyed, making the viewers find buildings misfit. It is necessary to analyze the age of the building and to remove moss, acid rot and other factors. The degree of how the buildings are worn is calculated according to the age, and then the digital image is restored. To some extent, although the wear of materials destroyed the structure of ancient buildings, it still attached a thick sense of history to the ancient buildings.



Figure 1. Digital image technology restoration demonstration of ancient buildings—Shangrao Yangchun Ancient Stage in Jiangxi Province.

With the rapid development of 3D software, we can now simulate all kinds of high-precision materials. For example, the software PBR (physical based rendering) can restore the original appearance of ancient building materials to a great extent based on physical material rendering. In the restoration of digital model material simulation, we can collect information of the existing ancient building from local materials. For the ancient buildings which are seriously damaged, 3D software material drawing can be used to restore their appearance. The combination of the two methods not only ensures the quality of digital model and material, but also improves the efficiency and greatly enriches the methods of designers to repair buildings.

\subsection{Research on the introduction of digital image technology of ancient architectural culture}

\subsubsection{Retrospection of cultural space within the boundary of ancient buildings.}

The interior structure of ancient Chinese architecture is solemn, and the central symmetry is often adopted, which complements each other. When the buildings are combined with calligraphy, painting, bonsai, and cultural relics antique, a kind of elegant mood can be created. Most of the precious properties of ornaments, such as culture, porcelain, calligraphy and painting, are due to the rarity of the culture they represent and the uniqueness of their history. This part of cultural content cannot be restored at the image level when it is produced. However, it is possible to trace back to the era of the construction of this ancient architecture, investigate the information such as 
the application pattern of the era, and re-carve its universal parts into the targeted digital model of ancient architecture through digital image technology.

\subsubsection{Development of cultural connotation of ancient buildings under the introduction of digital image technology.}

The charm of ancient architectural culture lies not only in the architecture itself, but also in its opera culture, poetry culture and aesthetic culture. When we appreciate ancient buildings, attention should be paid not only to their external aesthetic characteristics, but also to their internal cultural charm through the brick walls and structural layout of ancient buildings[5]. Under the introduction of digital image technology, these cultural connotations will radiate new vitality.

The transmission channel and form of the vast majority of the ancient architectural culture in China is monotonic. With the development of China's tourism industry, cultural tourism resources are developed in various regions, and the market competition is increasingly fierce. The digital image technology and ancient architectural culture have been explored in their combination. The most successful case is the virtual demonstration system of the Palace Museum. The system comprehensively and vividly shows the Palace Museum's architecture, history, cultural relics, culture and art, palace life and other aspects. It has created huge revenue for the Forbidden City, and also promoted the development of IP (intelligent property) products for the Forbidden City. The feasibility of this move is verified by development of cultural image technology of the Forbidden City, which will form a new way of cultural communication of ancient buildings in the future. The cultural value of urban ancient architecture can be passed to the public through cultural tourism and cultural experience activities, forming a virtuous circle of urban ancient architecture protection and cultural heritage.

\subsection{Rethinking of digital image technology on cultural communication in the context of information age}

The advent of $5 \mathrm{~g}$ era makes our data transmission upgrade to a higher level, which enables video media transmission improve its speed and expand its scope. The cultural image products, with the introduction of digital image technology, is characterized with small size, concise content and strong visual effect, which can make ancient buildings stand out in many tourist attractions. The cultural source of ancient architecture gets rid of the shackle of traditional transmission methods such as pictures and text while introducing media resources which contain more and larger information content.

The expressive power of digital image technology can give full play to the imagination and expression of designers. On this basis, more ancient architectural culture can be introduced into digital image technology, such as digital image Museum, ancient architectural culture IP games and animation works. Some new ways of images and culture transmission, such as WeChat official account, micro-blog, and short video of Tiktok create infinite possibilities for the transmission of ancient architectural culture.

\section{Conclusion}

Under the background where culture and tourism are integrated, the ancient architectural culture should be taken as the core and combined with new digital image technology in order to upgrade the communication content of the ancient architectural culture and build the brand of it in newly expanded channels and promoted platforms. Technology is only a method which serves to foster the core force-cultural connotation. How to implant more ancient architectural culture into image technology is the key point to advance the core of ancient architectural culture. Digital image technology has become a new trend to promote ancient architectural culture. On the one hand, it can create a culture brand of ancient buildings, which promotes the development of local economy and increases people's sense of cultural belonging. On the other hand, it can push forward the diversified development of that culture and meet people's spiritual needs. Introducing modern digital image technology into culture can realize the deep integration of technology and culture, which provides countless possibilities for the transmission of ancient architectural culture.

\section{References}

1. Xu, S. Y. (2016) Research on app design of ancient architecture with the unified synchronicity and diachronicity. Hunan Normal University, 10-14.

2. Wang, R. (2010) Research on key technologies of digitization and 3D modeling of ancient buildings. Northwest University, 2-6.

3. Zhang, Y. (2019) Analysis on the protection methods of ancient buildings in traditional villages. Jushe, 33: 17.

4. Yang, S. G. (2019) Research on visual restoration of French big wood craft based on UE4 engine. Shanxi Architecture, 45(22): 5-8.

5. Luo, J. N. (2020) Cultural Marketing Strategies for the protection of urban Ancient buildings and cultural heritage-taking the Chen Family Temple in Guangzhou as an example. Shanghai Urban Management, 28(01): 32-39.

6. Wang, D. T. (2018) Design and Implementation of Ancient Building Virtual Simulation Augmented Reality Map Product. Hunan Normal University, 1214. 